
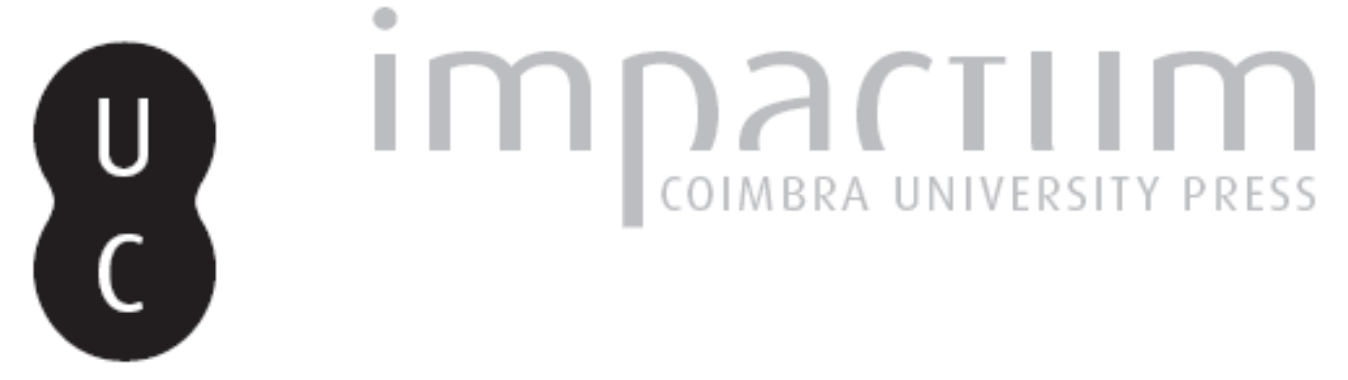

O socorro e a sua organização: funções dos municípios e dos corpos de bombeiros: subsídios para o estudo da sua evolução nos últimos cinquenta anos

Autor(es): $\quad$ Laranjeira, José António da Piedade

Publicado por: Associação Portuguesa de Riscos, Prevenção e Segurança

URL persistente:

URI:http://hdl.handle.net/10316.2/36176

DOI:

DOI:http://dx.doi.org/10.14195/1647-7723_16_21

Accessed : $\quad$ 26-Apr-2023 14:40:08

A navegação consulta e descarregamento dos títulos inseridos nas Bibliotecas Digitais UC Digitalis, UC Pombalina e UC Impactum, pressupõem a aceitação plena e sem reservas dos Termos e Condições de Uso destas Bibliotecas Digitais, disponíveis em https://digitalis.uc.pt/pt-pt/termos.

Conforme exposto nos referidos Termos e Condições de Uso, o descarregamento de títulos de acesso restrito requer uma licença válida de autorização devendo o utilizador aceder ao(s) documento(s) a partir de um endereço de IP da instituição detentora da supramencionada licença.

Ao utilizador é apenas permitido o descarregamento para uso pessoal, pelo que o emprego do(s) título(s) descarregado(s) para outro fim, designadamente comercial, carece de autorização do respetivo autor ou editor da obra.

Na medida em que todas as obras da UC Digitalis se encontram protegidas pelo Código do Direito de Autor e Direitos Conexos e demais legislação aplicável, toda a cópia, parcial ou total, deste documento, nos casos em que é legalmente admitida, deverá conter ou fazer-se acompanhar por este aviso.

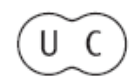




\section{territorium}

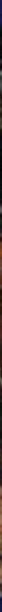

16

Revista da Associação Portuguesa de Riscos, Prevenção e Segurança 2009 


\title{
O SOCORRO E A SUA ORGANIZAÇÃO: FUNÇÕES DOS MUNICÍPIOS E DOS CORPOS DE BOMBEIROS. SUBSÍDIOS PARA O ESTUDO DA SUA EVOLUÇÃO NOS ÚLTIMOS CINQUENTA ANOS*
}

\author{
José António da Piedade Laranjeira \\ Ex-Presidente do Serviço Nacional de Bombeiros
}

\section{Introdução}

Neste trabalho são postas em evidência as raízes de uma divisão territorial, onde os concelhos e as freguesias têm raízes profundas na vida das populações do nosso país e as responsabilidades que, muito naturalmente, recaem nos seus dirigentes, os autarcas, particularmente as responsabilidades que se reflectem na segurança, na protecção e no socorro. São referidas questões relacionadas com a necessidade de conhecer os riscos do território municipal e do modo como, na área da protecção e socorro, ao longo dos anos, têm sido tomadas iniciativas por parte dos Municípios, das suas populações e do Governo, para prever os riscos e reduzir as suas consequências.

É posto em destaque o fosso que ainda hoje, de um modo geral, se verifica entre os Municípios e as Associações Humanitárias de Bombeiros Voluntários que administram Corpos de Bombeiros que são, na maioria dos Municípios portugueses, o primeiro e principal agente de protecção e socorro na área territorial desses Municípios.

Por último refere-se a necessidade básica da Associação Nacional de Municípios Portugueses ser o motor para que, com a Autoridade Nacional de Protecção Civil e a Liga dos Bombeiros Portugueses, se estabeleçam normas estruturais do relacionamento entre os Municípios e as Associações Humanitárias de Bombeiros Voluntários.

\section{Os municípios e os meios de protecção e socorro criados nas suas áreas territoriais}

\section{Uma referência à origem dos Municípios}

Os Municípios/Concelhos são a forma tradicional da administração local. A sua origem é helénica e foram evoluindo ao longo dos séculos com a maior ou menor representatividade dos cidadãos que viviam e trabalhavam nas suas áreas territoriais e em que não se deixava de destacar as diferenças de classe a nível social e as suas influências na selecção dos responsáveis locais pela gestão da coisa pública, pela aplicação da justiça etc.

Juiz, Alcaide, Alvazil ou Aguazil, Almotacel, Vereador, Administrador de Concelho, etc, foram algumas das designações dos que, ao longo dos tempos, foram responsáveis por governar e defender, castelos, vilas, cidades, províncias, comarcas, distritos, sendo ainda, em alguns períodos, os conselheiros de reis e príncipes. Por exemplo o termo "Vereador", ainda hoje designação corrente dos elementos que acompanham o Presidente da Câmara Municipal na gestão executiva do Município, já era referido em 1351 nos seguintes termos... "vereadores dos ditos luguares fizeram ora novamente sua vereaçam"

As Freguesias surgiram no governo de Passos Manuel, em 1836, quando de uma reforma administrativa foram eliminados alguns Concelhos e então criada a figura da Freguesia ou Paróquia Eclesiástica.

Com estas referências pretende-se por em evidência como estão bem integradas nas nossas comunidades as actuais Freguesias, com o sua Junta de Freguesia como órgão executivo e a Assembleia de Freguesia, como órgão deliberativo e fiscalizador e os Municípios com os seus dois órgãos - o executivo - a Câmara Municipal e o deliberativo e fiscalizador - a Assembleia Municipal.

A evolução dos meios de protecção e socorro desenvolvidos pelas autarquias, pelos cidadãos e pelo Governo:

\section{Corpos de Bombeiros Municipais}

Desde sempre os riscos naturais como inundações, maremotos, tremores de terra, erupções vulcânicas, deslizamento de terras, incêndios, tornados, secas, etc, preocuparam as comunidades, mas, do que se conhece no nosso país, ao longo de séculos, o risco que teve resposta mais atenta e mais pronta foi o dos incêndios urbanos, conforme se pode acompanhar desde a Carta Régia de D.João I (1395), ao contrato de fiscais para verificar se os lumes eram apagados à noite (1513), ao primeiro regulamento para o serviço de incêndios (1683), à constituição de Corpos de Bombeiros com as mais distintas designações - esquadra da bomba, companhia da bomba, companhia do fogo, companhia da bomba do fogo, companhia de incêndios, serviço de socorro contra incêndios, corpo de bombeiros municipais, etc. - nas cidades, como Porto, Lisboa, Viana do Castelo, Coimbra, Braga, Setúbal, Abrantes, Viseu, Vila Nova de Gaia, Figueira

* Conferência proferida durante o V Encontro Nacional e I Congresso Internacional de Riscos, durante a Mesa Redonda 2, subordinada ao tema: A organização do socorro na transição de milénios, na perspectiva dos ex-Presidentes do Serviço Nacional de Bombeiros. 
da Foz, Santarém, Faro, Tavira, Funchal, Olhão, Lousã, Tomar, Coruche, Santa Cruz, Cartaxo, Loulé, Alcanena, Alpiarça, Gavião, Sardoal, Machico, hoje ainda activas e ainda outras como Lamego, Guimarães, Barcelos, Penafiel, Valença, Peso da Régua, Bragança, Vila Real, Vila do Conde, Vila Nova de Famalicão, Póvoa do Varzim, Ponta Delgada, Ribeira Grande, Benavente, Castelo Branco, Portalegre, Aveiro, Beja, Cascais, Oliveira de Azeméis, etc, já extintas.

Esta dispersão ao longo de todo o país continente e regiões autónomas - põe em evidência a pressão que a probabilidade de ocorrência de acidentes impunha aos autarcas, provocando a necessidade de the darem uma resposta e originando a criação de Corpos de Bombeiros para reduzir os efeitos desses riscos.

Este resposta dos municípios perante os riscos que se iam conhecendo, assumida naturalmente, acabou por ser referida oficialmente nos Códigos Administrativos como uma obrigação ou dever, de que são exemplo os de 1878 e de 1900 em que se diz, por exemplo, no de 1878 - "...compete às Câmaras organizar serviços ordinários e extraordinários para extinção de incêndios... e contra inundações...." e no de 1900 "...responsabilidade de deliberar: Sobre a organização de serviços para a extinção de incêndios e para prevenir ou atenuar os males resultantes de calamidades públicas... competindo ao administrador do concelho providenciar para protecção e segurança das pessoas e cousas nos casos de incêndio, inundações, naufrágios, calamidade pública e semelhantes, promovendo a prestação e distribuição de socorro".

\section{As Associações Humanitárias de Bombeiros Voluntários}

Mas as dificuldades financeiras que caracterizavam as autarquias durante muitos anos, só melhoradas após a Revolução de Abril de 1974, levou a que os cidadãos, perante as manifestações de reduzida capacidade operacional das instituições criadas pelos Municípios, se unissem e em verdadeiro espírito de solidariedade, constituíssem as Associações Humanitárias de Bombeiros Voluntários.

A primeira associação foi fundada em Lisboa no ano de 1868 e esta iniciativa teve tal projecção no país que até ao ano de 1900 foram criadas 76 (setenta e seis) dessas associações desde Monção a Vila Real de Santo António, de Almoçageme a Portalegre e ainda à parte insular de Portugal.

Estas associações vieram originar a extinção de várias das organizações municipais e, basicamente, colmatar a falta dessas instituições na maioria dos Municípios do país.
Hoje, juntaram-se às setenta e seis do século XIX mais trezentas e sessenta dessas associações que fazem a cobertura, em primeira chamada, dos riscos naturais que deram origem à sua criação e procuram corresponder aos novos riscos ditos tecnológicos, que o desenvolvimento industrial originou como: acidentes de produção industrial, de produção química e de armazenamento e transporte dos mesmos produtos, acidentes biológicos, radiológicos, rupturas de barragens, poluição marítima etc.

Assim, as Associações Humanitárias de Bombeiros Voluntários, emanadas das populações locais e com os seus órgãos sociais e elementos dos seus Corpos de Bombeiros originários dessas mesmas populações são, na maioria dos Municípios portugueses, as entidades que dão resposta aos problemas de protecção e socorro a nível municipal e até intermunicipal.

\section{A Liga dos Bombeiros Portugueses}

As dificuldades levaram as Associações a organizarem-se e agruparem-se em confederações desde o princípio do Séc. XX e depois de várias tentativas falhadas teve êxito a criação, em 1930, com estatutos aprovados em 1932, da Liga dos Bombeiros Portugueses que ao longo dos anos tem vindo a prestar relevantes serviços aos bombeiros em geral e ao país, com as suas iniciativas que têm vindo abordar áreas como o social, o operacional, a formação, o equipamento e fardamentos, a colaboração na preparação de legislação do sector, etc.

No entanto, e na ausência de iniciativas da estrutura entretanto estabelecida, com o continente dividido em duas zonas - Inspecções Regionais uma com sede em Lisboa-Sul e outra no Porto-Norte, sob a responsabilidade dos respectivos comandantes dos Batalhões de Sapadores de Bombeiros de Lisboa e Porto, começaram-se a organizar reuniões de Comandos dos Corpos de Bombeiros, como se verificou em 1965, com os Comandos do Distrito de Aveiro. Esta primeira reunião teve lugar em Albergaria-a-Velha, e seguiram-se outras, pois a necessidade de estabelecer contactos e relações, trocar experiências, promover sessões de formação, etc, era considerado básico e de tal modo se desenvolveu que, pouco tempo depois, se iniciaram as reuniões dos Directores das Associações, pois os projectos dos Comandos precisavam do apoio dos órgãos sociais e de tais iniciativas resultou a constituição de uma estrutura a nível distrital - B.D.A. - Bombeiros do Distrito de Aveiro (Comandos e Direcções) que, em 1975, deu origem à primeira Federação do país, a Federação dos Bombeiros do Distrito de Aveiro. 
Ainda com a organização dos BDA, teve lugar em Aveiro, em 1970, o XIX Congresso da Liga dos Bombeiros Portugueses, onde se defendeu a criação de um organismo superior e autónomo com directa jurisdição na orgânica e dinâmica dos Bombeiros Portugueses. Desta tomada de posição, reforçada em posteriores Congressos da Liga, resultou a legislação que veio permitir criar o pretendido organismo que seguir se comenta.

\section{O Serviço Nacional de Bombeiros}

Depois de 1974, verificaram-se condições de ordem política que permitiram fazer aprovar pela Assembleia da República a Lei no 10/79 de 10 de Março, que veio dar origem ao Serviço Nacional de Bombeiros (SNB), - Dec.-Lei n. $.418 / 80$, de 29 de Setembro -, hoje, infelizmente, já extinto.

Com a criação e estabilização do SNB, deu-se início ao período de maior progresso dos Bombeiros Portugueses, em particular dos voluntários, no continente, já que os Bombeiros das Regiões Autónomas foram abrangidos por diplomas específicos.

Com receitas próprias em que avultam as taxas aplicadas aos prémios de seguros e as verbas do orçamento geral do Estado, projectam-se campanhas de formação que vão culminar com o lançamento da Escola Nacional de Bombeiros, formação que contou, entre outras, com a colaboração da Cruz Vermelha Portuguesa, Instituto Nacional de Emergência Médica, Escola de Limitação de Avarias da Armada Portuguesa, Direcção-Geral das Florestas e Instituto de Socorros a Náufragos. Recebemos o apoio de formadores estrangeiros e enviámos a países amigos vários grupos para frequentarem cursos em diversas áreas, etc.

Programaram-se campanhas de equipamentos viaturas ligeiras de combate a incêndios urbanos e florestais, autotanques, material de desencarceramento, ambulâncias, motobombas, equipamento de protecção individual, rádios, criação dos CCOs Centros de Coordenação Operacional, em diversos pontos do país; Centro de Coordenação de Meios Aéreos, apoio à construção de heliportos, de campos de aviação e de quartéis e lançaram-se os Comandantes Operacionais e como não foi fácil esta tarefa em função de alguns bairrismos exagerados e retrógrados.

Neste período, surgiram dificuldades no relacionamento com algumas Câmaras Municipais, em particular com as que tinham e têm os seus Corpos de Bombeiros Municipais, pelo facto de que deixaram de ter como receita própria, parte das taxas para o serviço de incêndios, o que nas Câmaras de Lisboa e do Porto se traduzia em verbas muito significativas. Para além disso, em Lisboa e no Porto os Batalhões de Sapadores de Bombeiros não se integraram na estrutura coordenadora/inspectora do SNB Inspecção Superior e respectivas Inspecções Regionais, a de Lisboa e Vale do Tejo e a do Norte.

Assim, foram aceites, no arranque do SNB, e no meu entender numa atitude de acordo de cavalheiros para evitar o agudizar da situação e tentar criar um futuro ambiente de outro tipo de relacionamento, os designados Comando Operacional Autónomo de Lisboa (COAL) e o Comando Operacional Autónomo do Porto (COAP). E se naquilo a que poderíamos chamar causa próxima estará a atitude da Arma de Engenharia, donde emanam os Comandos dos Batalhões, em não aceitar que os seus oficiais ficassem na dependência hierárquica do Inspector Superior e Inspector Regional, na génese estará o forte corte nas receitas oriundas do imposto de incêndios, não deixando de ter também em consideração o princípio de que "manda quem paga" e aos Corpos de Bombeiros Municipais quem paga são as Câmaras Municipais.

Devo pôr em nota que o relacionamento entre o SNB, os Batalhões e as respectivas Câmaras Municipais, enquanto fui Presidente do SNB, foram as mais correctas, tendo inclusive o SNB, participado no desenvolvimento do processo que elevou 0 Batalhão de Lisboa a Regimento.

Em verdade, se sempre se reclamou do que se passava antes da criação do SNB, em que os maiores beneficiários das receitas eram os grandes centros populacionais, em particular Lisboa e o Porto, ficando para o resto do país verbas muito reduzidas, temos que reconhecer que, posteriormente, se originou uma injustiça para os Municípios que mantêm Corpos de Bombeiros Municipais pelo que entendemos que tal situação deve ser corrigida, o que adiante não deixaremos de destacar.

Conhecedor desta situação de diminuição de receitas, sempre se procurou estabelecer com os Municípios um relacionamento que permitiu desenvolver parcerias no apoio, por exemplo, na construção de heliportos, pistas de aviação, centros de coordenação operacional, formação, etc.

\section{A Protecção Civil: O Serviço Nacional de Protecção Civil e sua evolução para a Autoridade Nacional de Protecção Civil}

Com a fundação em 1931, em Paris, pelo General médico Georges Saint Paul, da Association des Lieux de Genéve, com o objectivo de criar condições de protecção para as mulheres, crianças e idosos, durante os períodos de guerra, foi dado o primeiro impulso para o desenvolvimento, a nível das nações, de organismos dedicados à protecção de pessoas e bens.

Esta associação em 1958 foi transformada na Organização Internacional de Protecção Civil, que 
em 1975 foi registada na ONU, tendo evoluído, de modo a não se dedicar só às situações resultantes dos conflitos armados, para uma nova noção de Protecção Civil que se alargou à protecção e segurança das populações em geral, devido à planificação, implementação e coordenação dos métodos, dos meios e das tecnologias, de modo a prevenir, combater e atenuar as consequências dos acidentes, catástrofes e calamidades de todos os géneros.

No nosso país a evolução foi semelhante e á organização criada pelo Estado Novo, que teve acção activa durante a II Guerra Mundial (19391945), designada por Defesa Civil do Território, segue-se uma nova organização - o Serviço Nacional de Protecção Civil (SNPC), Decreto-Lei n.. 78/75, de 25 de Fevereiro. Em 25 de Outubro de 1980, pelo Decreto-Lei n. -510 , regulamenta-se o SNPC, documento que apresenta a seguinte definição de protecção civil: "...a protecção civil compreende o conjunto de medidas destinadas a proteger o cidadão como pessoa humana e a população no seu conjunto de tudo o que represente o perigo para a sua vida, saúde, recursos, bens culturais e materiais, limitando os riscos e minimizando os prejuízos quando ocorram sinistros, catástrofes ou calamidades, incluindo os imputáveis à guerra".

A vida do SNPC foi-se desenvolvendo, em minha opinião, sempre com múltiplas dificuldades e limitações, apesar de ter tido na sua presidência ilustres Oficiais-Generais e na sua estrutura central e regional colaboradores muito competentes. Com este serviço foram desenvolvidas, conjuntamente com o SNB dos anos oitenta, acções muito positivas em particular na área da prevenção e até na luta contra os fogos florestais. Depois de um período de alterações em que se verificaram as tentativas da sua substituição por outros tipos de organismos intitulados Serviço Nacional de Protecção Civil e Bombeiros (organismo contestado pelos Bombeiros) e de Serviço Nacional de Bombeiros e Protecção Civil, este último uma autêntica aberração para a qual nunca consegui obter justificação racional, foi publicada a nova Lei de Bases da Protecção Civil Lei n.․ 27/2006, de 3 de Julho, em que se indica no seu capítulo IV, como novo organismo, a Autoridade Nacional de Protecção Civil (ANPC), que tem como lei orgânica o Dec.-Lei n.ำ 75/2007, de 29 de Março.

Este novo organismo, tem por missão "...planear, coordenar e executar a política de protecção civil, designadamente na prevenção e reacção a acidentes graves e catástrofes de protecção e socorro de populações..." missão que é completada por "...e superintendência da actividade dos bombeiros".

Por esta última referência, a sua estrutura orgânica apresenta uma direcção de serviços que trata dos
Bombeiros, isto é, tem no seu seio um dos agentes da protecção civil, mas só este, pois todos os outros agentes da protecção civil têm a sua estrutura independente deste organismo, embora por ele devam ser coordenados nas suas actuações. Um assunto a merecer futura reflexão, em função do decorrer do tempo e das experiências no terreno. Aliás este organismo traduz a tendência que já se verificava há muito e que teve uma primeira tentativa oficial com a constituição do então chamado Serviço Nacional de Protecção Civil e Bombeiros, que foi afinal, na prática, concretizado com este novo organismo.

As responsabilidades das Autarquias Locais a nível dos riscos nas suas áreas territoriais

Já se referiu como, desde sempre, os Municípios (Câmaras Municipais) procuraram responder aos riscos e como tal desiderato se tem vindo a expressar em documentos oficiais de que é bem representativa a nova Lei de Bases da Protecção Civil, muito clara quanto ao envolvimento das autarquias locais na protecção civil como se verifica na definição do conceito de Protecção Civil e no seu restante articulado:

"A protecção civil é a actividade desenvolvida pelo Estado, Regiões Autónomas e autarquias locais, pelos cidadãos e por todas as entidades públicas e privadas com a finalidade de prevenir riscos colectivos inerentes a situações de acidente grave ou catástrofe, de atenuar efeitos e proteger e socorrer as pessoas e bens em perigo quando aquelas situações ocorram".

Do seu conteúdo tiram-se assim referências como:

a) A actividade de protecção civil é desenvolvida pelo Estado, Regiões Autónomas, Autarquias Locais, cidadãos, Entidades Públicas e Privadas;

b) A estrutura da protecção civil organiza-se a nível Nacional, Regional e Municipal;

c) Consoante a natureza dos acontecimentos a prevenir ou a enfrentar a gravidade e extensão dos seus efeitos actuais ou potenciais, as medidas a tomar podem ter âmbito Inframunicipal, Municipal, Ultramunicipal e Nacional;

d) Cabe ao Presidente da Câmara Municipal, no exercício de funções de responsável municipal da política de protecção civil, desencadear, na iminência ou ocorrência de acidente grave ou catástrofe, as acções de protecção civil de prevenção, socorro, assistência e reabilitação adequadas em cada caso.

Mas o envolvimento das autarquias locais é reforçado e mais especificado na Lei no $65 / 2007$, de 12 de Novembro que refere, em relação aos objectivos 
e actividade da protecção civil municipal, entre muitos outros aspectos, os seguintes, que considero básicos:

a) Prevenir no território municipal os riscos colectivos e a ocorrência de acidentes graves ou catástrofes deles resultante;

b) Socorrer e assistir no território municipal as pessoas e outros seres vivos em perigo e proteger bens e valores culturais, ambientais e de elevado interesse público".

Estes dois itens estão na base do que a seguir comento.

\section{Os municípios e as Associações Humanitárias de Bombeiros Voluntários}

\section{A opção dos Municípios em função dos riscos}

1. Com o que se foi descrevendo, pretendeu-se pôr em destaque o reconhecimento, desde sempre, pelo homem, dos riscos que o rodeiam, de algumas medidas que por iniciativa dos órgãos da sua estrutura organizativa territorial local ou nacional ou dos próprios cidadãos, na ausência ou deficiência de actuação desses órgãos, se foram desenvolvendo e pelo que, a nível do Estado, se foi estruturando na tentativa de dar resposta adequada e organizada à definição, previsão e actuação em relação aos riscos e às suas consequências.

2. Pelo referido também se torna evidente que as acções a desenvolver na área da protecção civil têm como responsáveis pela base de análise e de acção os órgãos públicos mais próximos dos cidadãos que são as autarquias locais, com principal destaque para os Municípios.

3. Se a responsabilidade das autarquias, como se refere na alínea a) acima descrita, "prevenir no território municipal os riscos colectivos e a ocorrência de acidentes graves ou catástrofes deles resultante", pode ser resolvida a nível de estruturas de gabinete e nos períodos normais de trabalho, pela Comissão Municipal de Protecção Civil e ou Serviço Municipal de Protecção Civil, já o segundo, referido na alínea b), "socorrer e assistir no território municipal as pessoas e outros seres vivos em perigo e proteger bens e valores culturais, ambientais e de elevado interesse público" exige a existência de uma estrutura operacional com meios humanos e materiais adequados ao tipo de risco que enfrenta e com resposta pronta e em permanência 24 em 24 horas todos os dias do ano, pelo que: i. São assim as Autarquias Locais, em particular os Municípios através do seu órgão executivo, a Câmara Municipal, a encontrar solução para terem no seu território, pelo menos, um Corpo de Bombeiros, pois estes, como se tem verificado ao longo dos tempos, são os reais garantes duma acção permanente, activa e na hora, na prestação do socorro às pessoas e bens em perigo;

ii. Para a existência de um Corpo de Bombeiros, em eficientes condições operacionais, num Município só reconheço duas hipóteses:

1. Ou o Município cria um Corpo de Bombeiros Municipal;

2. Ou estabelece com uma (ou mais) Associação Humanitária de Bombeiros Voluntários um Protocolo de Prestação de Serviços, onde se definam as responsabilidades do Município perante a (as) Associação e se descrevam as condições dos serviços a prestar pelo Corpo de Bombeiros da Associação.

Considerando que esta última hipótese é a mais viável, mais racional e económica, no panorama nacional, onde o número de Associações é da ordem das quatrocentas e trinta e seis (23 nas Regiões Autónomas e 413 no Continente) e porque o que me parece lógico é que os Municípios a analisem, vou apresentar alguns considerandos sobre a vida das Associações e o seu relacionamento com os Municípios.

\section{A vida das Associações Humanitárias de Bombeiros Voluntários}

Desde sempre que as Associações encontraram grandes dificuldades na manutenção dos seus Corpos de Bombeiros e conseguiram sobreviver porque:

1. São apoiadas pelas populações donde emanaram, de forma continua com associados e com apoios eventuais, em dinheiro ou em espécie, de beneméritos;

2. Recolhem fundos na organização de festas, espectáculos, etc;

3. Nos tempos actuais obtêm receitas de alguns serviços prestados à comunidade, onde avultam os da área da saúde (transporte de doentes);

4. Têm, algumas das Associações, acordos de prestação de serviços de emergência com o Instituto Nacional de Emergência Médica;

5. Recebem apoios das entidades oficiais, principalmente depois da criação do Serviço Nacional de Bombeiros, hoje continuado pela Autoridade Nacional de Protecção Civil. 
Nota: Tem-se publicado legislação que estabelece algumas normas sobre alguns dos apoios oficiais como:

- Portaria n. $.1562 / 2007$, de 15 de Outubro Programa de Apoio Infra-Estrutural (PAI) às Associações Humanitárias de Bombeiros, que actualiza as normas já existentes nos apoios para beneficiação, ampliação e construção de quartéis.

- Portaria n. ${ }^{\circ}$ 104/2008, de 5 de Fevereiro Programa Permanente de Cooperação (PPC) com as Associações Humanitárias de Bombeiros, para os apoios no ano de 2008, que está em vigor.

Esta portaria, em minha opinião, apresenta um aspecto muito positivo para as Associações e para a Autoridade Nacional, já que juntou num valor global único os subsídios para efeitos de segurança social, combustíveis, taxas de rádio e os relativos aos jogos da Santa Casa da Misericórdia de Lisboa.

6. Os Governos Civis, de um modo geral, também apoiam, embora intermitentemente, as Associações;

7. Apoios das Autarquias Locais:

a) De algumas Juntas de Freguesia, autarquias que, de um modo geral, tem orçamentos muito reduzidos;

b) Dos Municípios (Câmaras Municipais), com apoios que vão merecer um comentário específico.

Os apoios dos Municípios às Associações Humanitárias de Bombeiros Voluntários

1. Os Municípios, de um modo geral, apoiam regularmente as Associações.

2. No entanto, verificam-se situações como:

- Poucos tem acordos pré-estabelecidos que definam os apoios a conceder durante o ano;

- Outros apoiam em função dos solicitações das Associações;

- Alguns apoiam as Associações de Bombeiros com os critérios que usam para apoiar os Grupos Folclóricos, as Bandas de Música, os Grupos Desportivos, etc.;

- Outros, por incompatibilidades pessoais ou políticas, normalmente deste último tipo, entre o Presidente da Direcção da Associação e o Presidente da Câmara, levantam dificuldades de diversa ordem para não concederem qualquer apoio ou reduzi-lo ou dilatá-lo no tempo.

3. Perante esta diversidade de critérios e de modos de actuação dos Municípios é de pôr a questão que se apresenta seguidamente:
Como devem os Municípios apoiar as Associações Humanitárias de Bombeiros Voluntários?

É na resposta a esta questão que está a base de garantir ao Presidente da Câmara e ao respectivo Município que a sua responsabilidade na área da Protecção Civil, no que diz respeito ao socorrer e assistir a pessoas e bens, está assegurada.

E como responder a esta questão básica?

1. Bastará à Câmara Municipal atender às solicitações das Associações, que tomaram deliberações sem qualquer prévio acordo com a Câmara, deliberações que normalmente arrastam consigo avultados encargos financeiros?

A resposta que considero correcta é a de um simples não, porque muitas Associações, solicitadas pelos Comandos dos seus Corpos de Bombeiros, tomam deliberações que envolvem avultados encargos, sem obterem, previamente o acordo de comparticipação do Estado e ou da Câmara Municipal, e lamentando-se publicamente da, em seu entender, falta de colaboração destas entidades, originam delicadas situações, em particular de ordem politica, para com o Presidente da Câmara e os seus pares.

Por exemplo, quantas vezes assisti, em cerimónias públicas das Associações, Presidentes das suas Direcções ou Comandantes dos Corpos de Bombeiros, criticarem a Câmara Municipal, porque em nada, ou pouco, tinha contribuído para a compra da nova viatura ou outro equipamento acabado de inaugurar, quando nada tinha sido acordado com a Câmara e a decisão da compra era exclusivamente da responsabilidade da Associação. E o mesmo poderia acrescentar quando o comentário se estendia ao organismo que representava- o SNB

2. Uma colaboração correcta baseia-se, como já se referiu, em a Câmara Municipal estabelecer com a, ou, as Associações um Protocolo de Prestação de Serviços, na base do qual deverão estar os documentos que:

a) Estabelecem os riscos da área territorial do Município,

b) Definem, em função destes Riscos, os meios humanos e materiais, mínimos para garantir um socorro adequado, em tempo e qualidade.

3. No que diz respeito aos riscos há necessidade de os definir na sua tipologia e níveis já que a Lei n. 65/2007, de 12 de Novembro (enquadramento institucional operacional da 
protecção civil de âmbito municipal) é bem clara quando no seu texto constam palavras como: Prevenir; Atenuar em território municipal os riscos colectivos e Socorrer, Assistir e Proteger no território municipal as pessoas e outros seres vivos, bens e valores culturais e ambientais em perigo, devido a ocorrências graves ou catástrofes deles resultantes.

Aliás, a mesma Lei não deixa dúvidas quanto à base de tudo aquilo que está para além da definição dos riscos a nível municipal quando refere, em relação aos objectivos da protecção civil municipal, as seguintes acções:

- Levantamento, Previsão, Avaliação e Prevenção dos riscos colectivos do Município;

- Planeamento de soluções de emergência, visando o salvamento e a prestação de socorro e assistência;

- Elaboração de Planos Prévios de Intervenção;

- Elaboração do Plano Municipal de Emergência;

- Planos especiais de Emergência:

i. Estes planos tem directivas relativas aos critérios e normas técnicas para a sua elaboração expressas na Resolução n. - $^{-}$ 25/2008, de 30 de Julho.

- Elaboração dos Planos de Prevenção e Combate aos Incêndios Florestais (já elaborado em muitos Municípios).

4. No que diz respeito aos meios humanos e materiais, como resposta aos tipos e níveis de risco, creio que a resposta só pode ser uma, a classificação de cada Município em função de vários itens, em que se destacam os dos riscos inerentes ao território municipal e dai resultar a classificação ou tipificação do, ou de cada um, dos Corpos de Bombeiros que existem na área do Município.

A Tipificação do Corpos de Bombeiros já tem a sua história e não posso deixar de a citar.

No final dos anos oitenta do século passado, como Presidente da Direcção do SNB apresentei no Conselho Superior de Bombeiros uma proposta que visava a classificação dos Corpos de Bombeiros Voluntários que por arrastamento classificava as respectivas Associações e permitiria ao SNB ter uma acção mais oportuna e justa em relação às necessidades operacionais de cada um. Além disso, esta classificação permitiria que os apoios do SNB se processassem administrativamente de um modo mais fácil e eficiente em relação aos processos então em curso que originavam uma pesada burocracia para as Associações e em particular para o SNB.

O processo foi evoluindo e já no mandato do meu sucessor Eng. Barreira Abrantes foi publicado o Decreto Regulamentar no 62/94 de 2 de Novembro que estabelece "O Regime Jurídico de Tipificação dos Corpos de Bombeiros"

Pelo que conheci, levantaram-se desde logo manifestações de desagrado por parte de Associações e o processo foi mais tarde revisto e completado com a publicação dos seguintes documentos:

- Decreto Regulamentar n. 9 41/97, de 2 de Outubro, que revogou o anterior acima referido;

- Portaria n. 1062/97, de 17 de Outubro que completa o Dec.-Regulamentar e onde se descreve a classificação dos Municípios e dos tipos de Corpos de Bombeiros nele existentes, quer sejam Municipais, Sapadores ou Voluntários.

Pelo que continuo a ouvir, este delicado trabalho, base para qualquer acção na área da Protecção Civil, não estará a ser devidamente utilizado e dúvidas não tenho em relação à definição do relacionamento que se deve desenvolver entre os Municípios e as Associações Humanitárias de Bombeiros Voluntários.

Creio que não poderei deixar de transcrever - que consta da introdução ao Dec.Regulamentar n. 41/97, onde se diz: "... esta classificação permite programar os meios necessários para responder às exigências específicas de cada corpo de bombeiros em função das características da área em que intervém e dos tipos e níveis de risco que the estão associados. Permite, ao mesmo tempo, balizar ou delimitar com maior rigor as responsabilidades do Estado nesta área, quer a nível do poder central, quer ao nível do poder local, eliminando critérios de discricionariedade ou puramente subjectivos."

Por tudo o que tenho vindo a descrever, estou totalmente de acordo com este texto que tudo diz sobre o que vem sendo o relacionamento dos Municípios com as Associações que, na maioria dos casos, se vem pautando por critérios muito subjectivos.

Em conclusão:

O relacionamento dos Municípios com as Associações Humanitárias de Bombeiros Voluntários, deve basear-se no seguinte:

- Os Municípios devem utilizar a Tipificação dos Corpos de Bombeiros em vigor onde se estabelecem as características base de cada Corpo de Bombeiros, características sobre as 
quais se devem formular os referidos Protocolos de Prestação de Serviços.

- Ou, se se verificarem divergências em relação à tipificação pela existência de riscos não considerados na avaliação, solicitar à Autoridade Nacional de Protecção Civil uma revisão da classificação.

\section{Quem deve assumir-se neste básico relacionamento entre os Municípios e as Associações Humanitárias?}

1. Considerando, pelo que se referiu ao longo deste trabalho, que a protecção civil a nível municipal está na base de tudo o que se possa desenvolver a nível distrital e nacional, considero que são três as entidades que tem que se juntar para vencer o desfasamento, a que chamo fosso (gap), que é uma realidade que se verifica a nível dos Municípios e as Associações. São elas:

- A Autoridade Nacional de Protecção Civil ANPC;

- A Associação Nacional dos Municípios Portugueses (ANMP);

- A Liga dos Bombeiros Portugueses (LBP), em interligação com as Federações Distritais.

2. Cada uma destas entidades tem as sua ligações bem conhecidas e nesta situação considero que o papel número um está na actuação da ANMP, porque:

a) Em minha opinião deve estar na primeira linha na definição das condições a estabelecer entre os seus associados, os Municípios e as Associações Humanitárias de Bombeiros Voluntários;

b) Se não o fizer, continua a perder a oportunidade de pôr os autarcas municipais, em particular os Presidentes das Câmaras Municipais, ao abrigo de delicadas e normalmente injustas situações políticas resultante da falta de esclarecimento das responsabilidades das Câmaras perante as Associações que, na sua liberdade de gestão, tomam, por vezes, decisões que originam desequilíbrios financeiros e acabam por apontar responsabilidades aos Municípios;

c) Sem uma clara definição das próprias responsabilidades das Associações em função das responsabilidades do Município na área da Protecção Civil, os autarcas não têm a garantia de que os Corpos de Bombeiros, administrados pelas Associações, tenham capacidade de resposta adequada aos riscos inerentes ao território municipal; d) Perde a oportunidade de estabelecer com - Governo a definição dos apoios financeiros a conceder aos Municípios para a área da Protecção Civil, em particular para os Municípios que têm Corpos de Bombeiros Municipais;

3. O que se acaba de referir já teve uma primeira realidade com o Protocolo estabelecido entre a Autoridade Nacional de Protecção Civil, a Liga dos Bombeiros Portugueses e a Associação Nacional dos Municípios Portugueses, referente à constituição das "Equipas de Intervenção Permanente", compostas por cinco elementos com a missão de assegurar, em permanência, o socorro às populações. (Portaria n. $.1358 / 2007$, de 15 de Outubro)

Este protocolo foi um primeiro passo, mas trata de uma situação pontual e para eliminar o fosso há que ir mais além e desenvolver medidas básicas, estruturais, que ponham as populações e os autarcas responsáveis pela sua segurança a coberto de surpresas desagradáveis perante os riscos inerentes aos territórios onde vivem ou trabalham.

\section{Conclusão}

1. Com a análise à evolução, ao longo das últimas décadas, das acções que foram sendo implementadas na área da Protecção e Socorro, com as sucessivas alterações de políticas na área da Protecção Civil, concluímos que:

a) É ao nível do Município que reside a base de uma "Protecção Civil", operante e eficaz;

b) Compete ao Município tomar as previdências básicas para que os riscos, existentes na área do território municipal, estejam devidamente definidos;

c) Compete ao Município preparar o plano municipal de emergência, os planos de emergência especiais e os planos prévios de intervenção;

d) Compete ao Município instalar, manter e dinamizar as estruturas referentes ao funcionamento da Comissão Municipal de Protecção Civil e do Serviço Municipal de Protecção Civil;

e) Compete ao Município providenciar a existência de, pelo menos, uma unidade operacional de intervenção, no seu território, pelo que, ou:

- Cria um Corpo de Bombeiros Municipal, ou

- Estabelece, com outra entidade, no caso 
normal no nosso país, com uma Associação Humanitária de Bombeiros Voluntários, um "protocolo de prestação de serviços", em que fiquem bem claras as responsabilidades de cada uma destas entidades;

2. Também se conclui que esta acção, na área da Protecção Civil a nível dos Municípios, exige contrapartidas financeiras para os Municípios, quer por via directa, quer por via de apoio aos Corpos de Bombeiros (Municipais e Voluntários);

3. Para que seja possível um relacionamento equilibrado e justo é fundamental que neste processo estejam envolvidas as seguintes entidades:

- A Autoridade Nacional de Protecção Civil, pelas suas responsabilidades na área da
"Protecção Civil" a nível Nacional, Regional e Municipal, bem como por ser a entidade que, actualmente, tem a superintendência da actividade dos bombeiros;

- A Liga dos Bombeiros Portugueses, que, nesta situação, representa as Associações Humanitárias de Bombeiros Voluntários;

- A Associação Nacional dos Municípios Portugueses, em representação dos Municípios seus associados e a quem, nesta fase da evolução da protecção e socorro, compete, em meu entender, dinamizar o processo.

Albergaria-a-Velha, Maio de 2009 